\title{
Two Xanthomonas Extracellular Polygalacturonases, PghAxc and PghBxc, Are Regulated by Type III Secretion Regulators HrpX and HrpG and Are Required for Virulence
}

\author{
Lifeng Wang, ${ }^{1,2}$ Wei Rong, ${ }^{1,2}$ and Chaozu He ${ }^{1}$ \\ ${ }^{1}$ State Key Laboratory of Plant Genomics, Institute of Microbiology, Chinese Academy of Sciences, Beijing 100101, \\ Peoples Republic of China; ${ }^{2}$ Graduate School of Chinese Academy of Sciences, Beijing, 100039, \\ Peoples Republic of China
}

Submitted 13 September 2007. Accepted 11 January 2008.

\begin{abstract}
Xanthomonas campestris pv. campestris, the causal agent of black rot disease, produces a suite of extracellular cell-wall degrading enzymes (CWDE) that are involved in bacterial virulence. Polygalacturonase (PG) is an important CWDE and functions to degrade the pectic layers of plant cell walls. Although previous studies have documented the virulence functions of PG in Erwinia and Ralstonia species, the regulation of $\mathbf{P G}$ genes still needs to be elucidated. In this study, we identified two novel PG genes (pghAxc and pghBxc) encoding functional PG from $X$. campestris pv. campestris 8004. The expressions of these two PG genes are regulated by the type III secretion regulators $\operatorname{HrpX}$ and HrpG and the global regulator Clp. These PG genes could be efficiently induced in planta and were required for the full virulence of $X$. campestris pv. campestris to Arabidopsis. In addition, these PG were confirmed to be secreted via the type II secretion system in an Xps-dependent manner.
\end{abstract}

Additional keywords: hydrolysis, pectin, pathogenesis.

The type II secretion system (T2SS) allows most gramnegative bacteria to deliver extracellular hydrolytic enzymes and toxins to their surroundings and hosts, many of which are responsible for pathogenesis in plants and animals (Sandkvist 2001a). Among the virulence factors secreted by the T2SS of phytopathogens, cell-wall degrading enzymes (CWDE), such as polygalacturonases (PG), cellulases, xylanases, and proteases, have been studied due to their clear or potential functions in bacterial pathogenesis, and comprehensive studies on the structures and functions of CWDE have been undertaken. CWDE function to break down the components of host cell walls and may play a crucial role in virulence and bacterial nutrition (Dow et al. 1990, 1998; Gonzalez and Allen 2003; Huang and Allen 1997; Kamoun and Kado 1990; Liu et al. 2005; Ray et al. 2000).

PG are hydrolytic enzymes of CWDE that selectively degrade the pectic polymers, the major components of higherplant middle lamellae and primary cell walls. PG are classified by activity as endo-PG (EC 3. 2. 1. 15) and exo-PG (EC

\section{Wang and W. Rong contributed equally to this work.}

Corresponding author: Chaozu He; Telephone: +1 86-10-62642536; Fax: +1 86-10-62548243; E-mail: hecz@im.ac.cn
3. 2. 1. 67). Endo-PG randomly hydrolyze polygalacturonic acid, releasing oligosaccharidic chains of variable length, whereas exo-PG release either galacturonate monomer, in the case of exoPG (EC 3.2.1.67), or dimmer (digalacturonate), in the case of exo-poly-a-D-galacturonosidase (EC 3.2.1.82), starting from the nonreducing end (Huang and Allen 1997). PG are produced by a wide range of fungal and bacterial phytopathogens to overcome the physical barriers composed of pectins and to provide abundant carbon resources inside the plant host. Their activities cause symptoms including leaf spot, soft rot, and wilt (Collmer and Keen 1986; Huang and Allen 1997). Although some aspects of expression regulation and the roles of pectolysis of PG have been studied in phytopathogens such as Erwinia spp. and Ralstonia solanacearum (Allen et al. 1997; Gonzalez and Allen 2003; Huang and Allen 1997; Hugouvieux-Cotte-Pattat et al. 1996, 2002; Nasser et al. 1999; Valls et al. 2006), the regulation and function of PG in Xanthomonas spp. have not been elucidated. Additionally, according to our alignment results, PG of Xanthomonas campestris pv. campestris appeared to differ from those reported, based on their nucleic-acid and amino-acid alignments. These differences may provide clues as to some new aspects of expression and function.

In many Xanthomonas species, HrpG and HrpX are two upstream regulators of $h r p$ genes in the type III secretion system (T3SS). HrpG regulates the expression of HrpX, an AraC-like transcription activator that controls a genome-wide regulon including $h r p$ genes and some effector genes (Buttner and Bonas 2002; Wengelnik et al. 1999). The HrpX-regulated promoters often carry a conserved motif termed the "plant-inducible promoter (PIP) box" and a -10 box (consensus, TTCGB-N ${ }_{15}$ TTCGB-N $30-32$-YANNNT) (Buttner and Bonas 2002; Furutani et al. 2006; Koebnik et al. 2006; Noel et al. 2003). The PIP box has been used as an effective marker to identify genes belonging to the HrpX regulon from the genome database. Recently, the specific binding of HrpX to corresponding PIP boxes has been reported (Koebnik et al. 2006).

$\mathrm{Clp}$ is a global regulator in $X$. campestris pv. campestris that encodes a homolog of the cAMP receptor protein (Crp) in Escherichia coli and functions as a regulator in exopolysaccharide and extracellular enzyme production (de Crecy-Lagard et al. 1990; Hsiao et al. 2005; Hsiao and Tseng 2002). Recent studies showed that Clp was involved in the transcriptional expression of about 299 genes, including a few that encode transcription factors (He et al. 2007). 
$X$. campestris pv. campestris, the causal agent of black rot disease, infects large numbers of crucifer plants (Williams 1980) and has been used as a model pathogen on studies of bacterial-plant interactions. $X$. campestris pv. campestris produces a range of extracellular enzymes that are collectively essential for pathogenesis (Dow and Daniels 1994). We have sequenced the whole genome sequence of $X$. campestris pv. campestris 8004, and analysis of the HrpX regulon showed that two genes of PG ( $p g h A x c$ and $p g h B x c$ ) contained a perfect PIP box, implying they might be regulated by HrpX. In this study, we demonstrated that PghAxc and PghBxc are functional PG and were required for the full virulence of $X$. campestris pv. campestris in Arabidopsis. pghAxc and pghBxc were independently regulated by the T3SS regulator $\mathrm{HrpX} / \mathrm{HrpG}$ and the global regulator Clp.

\section{RESULTS}

\section{Characterization}

of two putative PG genes, pghAxc and pghBxc.

Genome analysis of the genes belonging to the HrpX regulon in X. campestris pv. campestris 8004 revealed two putative

Table 1. Polygalacturonase (PG) activities of Xanathomonas campestris pv. campestri 8004 strains

\begin{tabular}{lcc}
\hline & \multicolumn{2}{c}{ PG activities } \\
\cline { 2 - 3 } Strains & Viscosity $^{\mathbf{a}}$ & $\begin{array}{c}\text { Reducing sugar ends } \\
\text { generated }^{\mathbf{b}}\end{array}$ \\
\hline 8004 (wild type) & 100 & $150 \pm 8.6$ \\
XCM31 (pghA mutant) & $85 \pm 4.1$ & $76 \pm 5.2$ \\
XCM32(pghB mutant) & $14 \pm 5.5$ & $110 \pm 6.4$ \\
\hline
\end{tabular}

${ }^{\text {a }}$ Change of the substrate viscosity as a percentage of wild-type level, indicating the primarily endo-PG activity as measured by change in viscosity of a polygalacturonic acid substrate solution.

${ }^{\mathrm{b}}$ Indicating the exo-PG activity by detecting the reducing sugar ends generated. Measured as units per $10^{9} \mathrm{CFU}$.
PG genes, pghAxc (Xc0705) and pghBxc (Xc1849), encoding the pectin-degrading enzymes, which have been assigned to the secreted extracellular CWDE of the T2SS (da Silva et al. 2002). However, both genes contained a perfect PIP box and a -10 box in their promoter regions (TTCGtttgcacggcagccggTT CGC-N ${ }_{30}$-TAGAGT in pghAxc and TTCGgcttggcggtgccgacTT CGC-N ${ }_{31}$-GATGGT in pghBxc), suggesting they might be HrpX-regulated (Furutani et al. 2006; Koebnik et al. 2006). Pfam analysis showed that PghAxc and PghBxc contained the glyco_hydro_28 (PF00295) domains, which belong to glycosyl hydrolase family 28 , which is associated with cell-wall degradation. Alignments of the PghAxc and PghBxc of $X$. campestris pv. campestris with the PG formerly studied from Erwinia spp. and $R$. solanacearum showed divergences but with some conserved catalytic domains; PghAxc is homologous with PehB (exo-PG, $R$. solanacearum) and PghBxc is homologous with PehA/pglA (endo-PG, $R$. solanacearum). However, PG in Xanthomonas species share nearly $80 \%$ similarity, suggesting that they may evolve conservatively for host-plant cell-wall degradation.

To characterize enzymatic function of endo- and exo-PG, viscometric assays and reducing sugar ends assays were performed. Measurement of viscosity demonstrated that the pghAxc mutant decreased the polygalacturonate substrate viscosity, comparing the wild-type strain and the $p g h B x c$ mutant (Table 1), suggesting that the PghBxc is an endo-PG. The reducing sugar ends assay showed that the enzyme activity of pghAxc mutant decreased to nearly $45 \%$ of the wild type, suggesting the PghAxc is an exo-PG (Table 1).

\section{Expression of $p g h A x c$ and $p g h B x c$ are regulated by HrpX and Clp.}

The perfect PIP boxes suggest HrpX-dependent expression. Previous studies have shown that Clp, a global transcription activator, regulates the transcriptions of many extracellular enzymes of $X$. campestris pv. campestris (de Crecy-Lagard et al. 1990; Hsiao and Tseng 2002; Hsiao et al. 2005). To test this

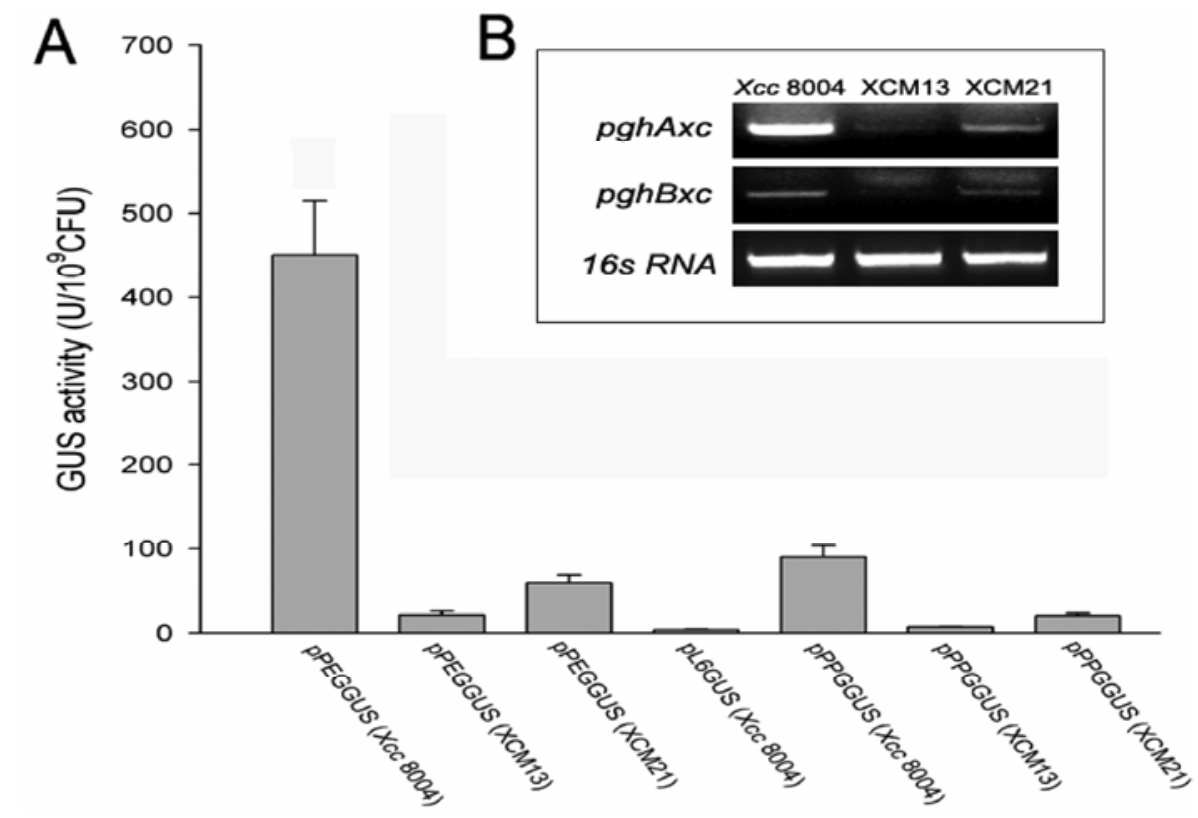

Fig. 1. Transcriptional expression of $p g h A x c$ and $p g h B x c$ are regulated by HrpX and Clp. A, Promoter- $\beta$-glucuronidase (GUS) activity assays of $p g h A x c$ and pghBxc in strains Xanthomonas campestris pv. campestris 8004, XCM13 (the hrpX mutant), and XCM21 (the clp mutant) in minimal medium MMXC (Wang et al. 2007). pL6GUS was introduced into X. campestris pv. campestris 8004 and was used as a negative control. Error bars represent standard deviations. 1 unit $=1 \mathrm{nmol}$ 4-methyl-umbelliferone produced per minute per bacterium. B, Reverse transcription-polymerase chain reaction analysis of $p g h A x c$ and $p g h B x c$ expression in wild type and the $h r p X$ and $c l p$ mutants. Equal amounts of total RNA pretreated with DNase I (RNase free) were used for firststrand cDNA synthesis. 16s RNA was used as control. 
transcriptional dependency, we cloned the promoter regions of pghAxc and pghBxc and fused them with $\beta$-glucuronidase (GUS) genes. GUS activities were assayed in wild type (X. campestris pv. campestris 8004), the hrpX mutant (XCM13), and the clp mutant (XCM21) strains in minimal medium (Wang et al. 2007). The results showed that the transcription activities of both $p g h A x c$ and $p g h B x c$ were impaired in the mutants of $h r p X$ and $c l p$. In particular, the activities in the $h r p X$ mutant were decreased to nearly $10 \%$ that of the wild-type $X$. campestris pv. campestris 8004 (Fig. 1A). Furthermore, we also found that $p g h A x c$ possesses higher transcriptional activity than pghBxc in $X$. campestris pv. campestris. These results were further confirmed by reverse transcription-polymerase chain reaction (RT-PCR), which was performed using cDNA synthesized from the total RNA from $X$. campestris pv. campestris 8004 and the mutants of $h r p X$ and clp cultured in minimal medium as templates (Fig. 1B).

\section{HrpG is involved in the regulation}

of pghAxc expression and is dependent on HrpX.

In Xanthomonas spp., it has been known that $\mathrm{HrpG}$ and HrpX are two linked upstream regulators of the T3SS, in which HrpG directly regulated the expression of HrpX (Buttner and Bonas 2002; Wengelnik et al. 1999). To investigate the regulation of HrpG on the two PG, we performed the promoter-GUS activity test in the wild-type strain, XCM11 (the hrpG mutant), XccOHrpG (hrpG overexpressed in wild type), and XCM13OHrpG (the $h r p X$ mutant strain with $h r p G$ overexpressed). The results showed that mutation in the $h r p G$ gene decreased the transcriptional activities of $p g h A x c$. Overexpression of $h r p G$ was able to enhance the transcriptional activities of $p g h A x c$, while with the mutated $h r p X$, the transcriptional activities of $p g h A x c$ decreased to a very low level (Fig. 2). The changes of the $p g h B x c$ transcript levels in these strains were not significant (data not shown). This result may be due to the weak expression of pghBxc. Cross-testing between HrpG/HrpX and Clp showed no significant relationship between them (data not shown), suggesting that regulation of PG by HrpG/HrpX and Clp might be independent in X. campestris pv. campestris.

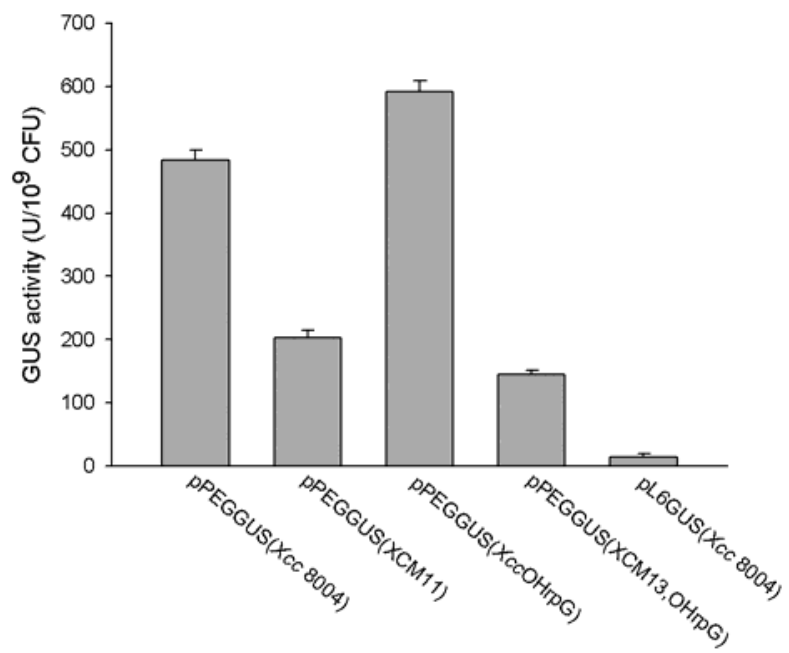

Fig. 2. HrpG regulates the transcriptional expression of pghAxc with the dependency on HrpX. Promoter- $\beta$-glucuronidase (GUS) activity assays of pghAxc in Xanthomonas campestris pv. campestris 8004, XCM11 (the hrpG mutant), XccOHrpG (hrpG overexpressed in wild-type $X$. campestris pv. campestris 8004), and the $h r p X$-mutated strain with $h r p G$ overexpressed in minimal medium MMXC (Wang et al. 2007). pL6GUS was used as a negative control. Error bars represent standard deviations. 1 unit $=1 \mathrm{nmol}$ 4-methyl-umbelliferone produced per minute per bacterium.
pghAxc and pghBxc can be efficiently induced in planta.

It has been reported that bacterial genes with a PIP box were mostly able to be induced in planta (Buttner and Bonas 2002). RT-PCR was performed to monitor the expression of pghAxc and $p g h B x c$ genes in planta using total RNA isolated from infected Arabidopsis (Col-0) leaves from 0 to $60 \mathrm{~h}$ after inoculation. The PCR products of pghAxc (639 bp) were clearly amplified from the RNA samples collected at 36, 48, and $60 \mathrm{~h}$ after inoculation compared with faint products at 12 and $24 \mathrm{~h}$. However, faint products of pghBxc $(960 \mathrm{bp})$ were only amplified from the Arabidopsis leaves $24 \mathrm{~h}$ after inoculation (Fig. 3A). The PCR products of $p g h A x c$ amplified at $0 \mathrm{~h}$, and products of $p g h B x c$ at 0 and $12 \mathrm{~h}$ were barely detectable (Fig. 3A). Tests have also been done using the $h r p X$ and $c l p$ mutant strains (XCM13 and XCM21) to inoculate Arabidopsis. However, we found that expressions of PG genes in planta could barely be detected with the mutated $h r p X$ or $c l p$ (Fig. 3B). These results further confirmed that the transcription of PG genes was dependent on the regulation of $\mathrm{HrpX}$ and Clp. Taken together, these results suggest that both PG genes can be efficiently induced in planta and are dependent on HrpX and Clp.

\section{PghAxc and PghBxc are secreted via the T2SS in an Xps-dependent manner.}

Previous studies show the PG of phytopathogens belong to the CWDE, which are secreted to the milieu via the T2SS (Liu et al. 2005; Sandkvist 2001b). The pghAxc gene encodes an exo-PG of $47 \mathrm{kDa}$, and pghBxc encodes an endo-PG of 60 $\mathrm{kDa}$. Analysis showed both of the two PG have N-terminal signal peptides (Center for Biological Sequence Analysis SignalP server). We computationally defined the signal peptide of PghAxc to the first 22 amino acids and PghBxc to 28 amino acids, which suggested the T2SS secretion of those two PG.

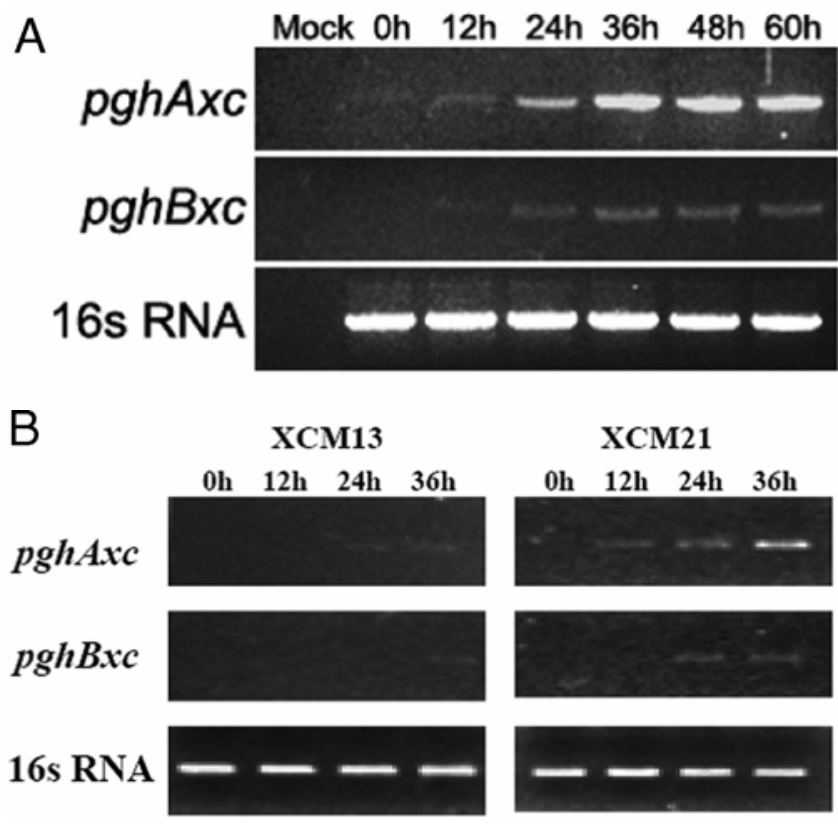

Fig. 3. Expression patterns of pghAxc and pghBxc in planta using A, Xanthomonas campestris pv. campestris 8004 and B, strains XCM13 and XCM21 as the inoculants. Total RNA of uninoculated Arabidopsis leaves (mock-inoculated) and leaves $0,12,24,36,48$, and $60 \mathrm{~h}$ after inoculation were used for first-strand synthesis in reverse transcription-polymerase chain reaction (RT-PCR). Amplification products of RT-PCR using pghAxc- and pghBxc-specific primers and 16s RNA-specific primers were visualized an agarose gel with ethidium bromide. The products of $16 \mathrm{~s}$ RNA were used as a control. 
Immunoblots were performed to test whether or not PghAxc and PghBxc are secreted via the T2SS. The pghAxc and pghBxc were fused by Myc tag at the C-terminus and were analyzed by the anti-Myc antibody. The constructs for providing the PG-Myc (pPghAMyc and pPghBMyc) were transformed into the strains of wild type (8004), the xpsE mutant (XCM25), and the $x p s D$ (XCM26) mutant. XpsE and XpsD are two key structural proteins of the $X$. campestris pv. campestris T2SS that structure the channel of the T2SS and determine secretion of the extracellular enzymes (Chen et al. 1996; Ray et al. 2000). Immunoblots of the proteins secreted by these strains in the minimal medium showed that in the cell-free supernatant of $X$. campestris pv. campestris 8004, both PghAxc and PghBxc could generate remarkable signals of detection (Fig. 4A). As opposed to the relatively substantive secretion of these two PG by the wild type, the secretion of these two PG by the two mutants ( $x p s E$ and $x p s D)$ was barely detectable in the culture, which suggests that PghAxc and PghBxc belong to the T2SS and secrete in an Xps-dependent manner (Fig. 4A). Furthermore, the PG activity assays using cell-free supernatant of the $x p s E$ and $x p s D$ mutants showed very low hydrolytic activities as compared with the wild-type strain $X$. campestris pv.
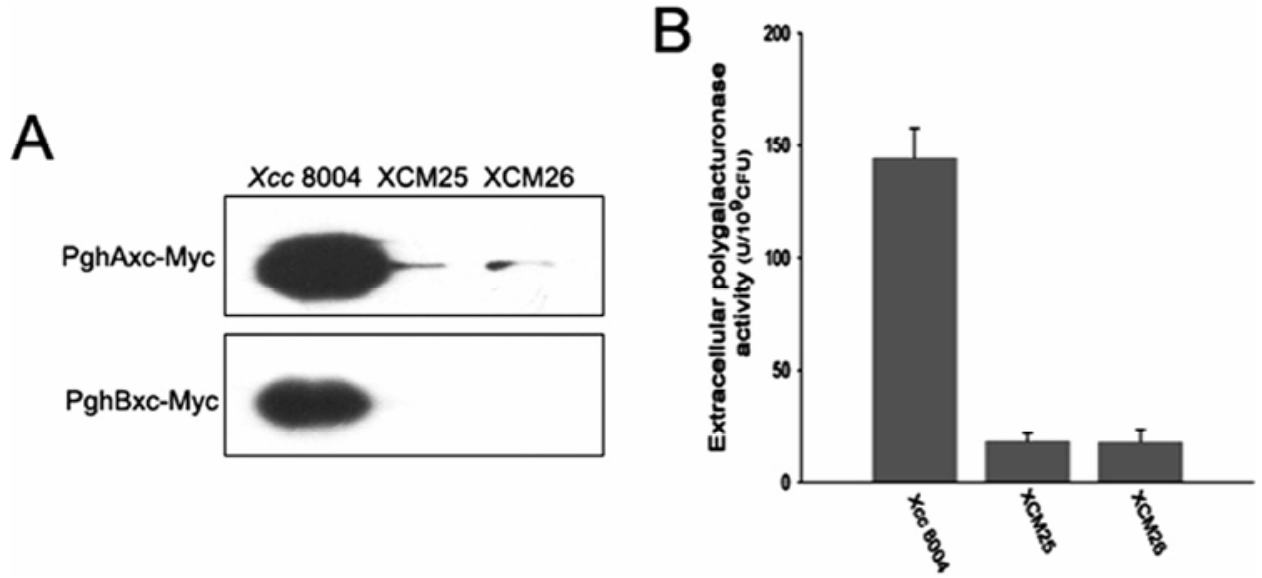

Fig. 4. PghAxc and PghBxc are secreted via the type II secretion system in an Xps-dependent manner. A, Immunoblot of secreted polygalacturonase (PG)Myc proteins in Xanthomonas campestris pv. campestris 8004, XCM25 (the xpsE mutant), and XCM26 (the xpsD mutant). Strains were cultured in minimal medium and the secreted proteins in culture fluids were collected. Equal amounts of concentrated secreted proteins were loaded onto sodium dodecyl sulfatepolyacrylamide gels and Myc antibodies were used for detection. B, Activity assays of the secreted PG in the culture fluids of wild-type and the xpsE and $x p s D$ mutants. Error bars represent standard deviations. A unit liberates $1 \mu \mathrm{mol}$ galacturonic acid from polygalacturonic acid per minute.
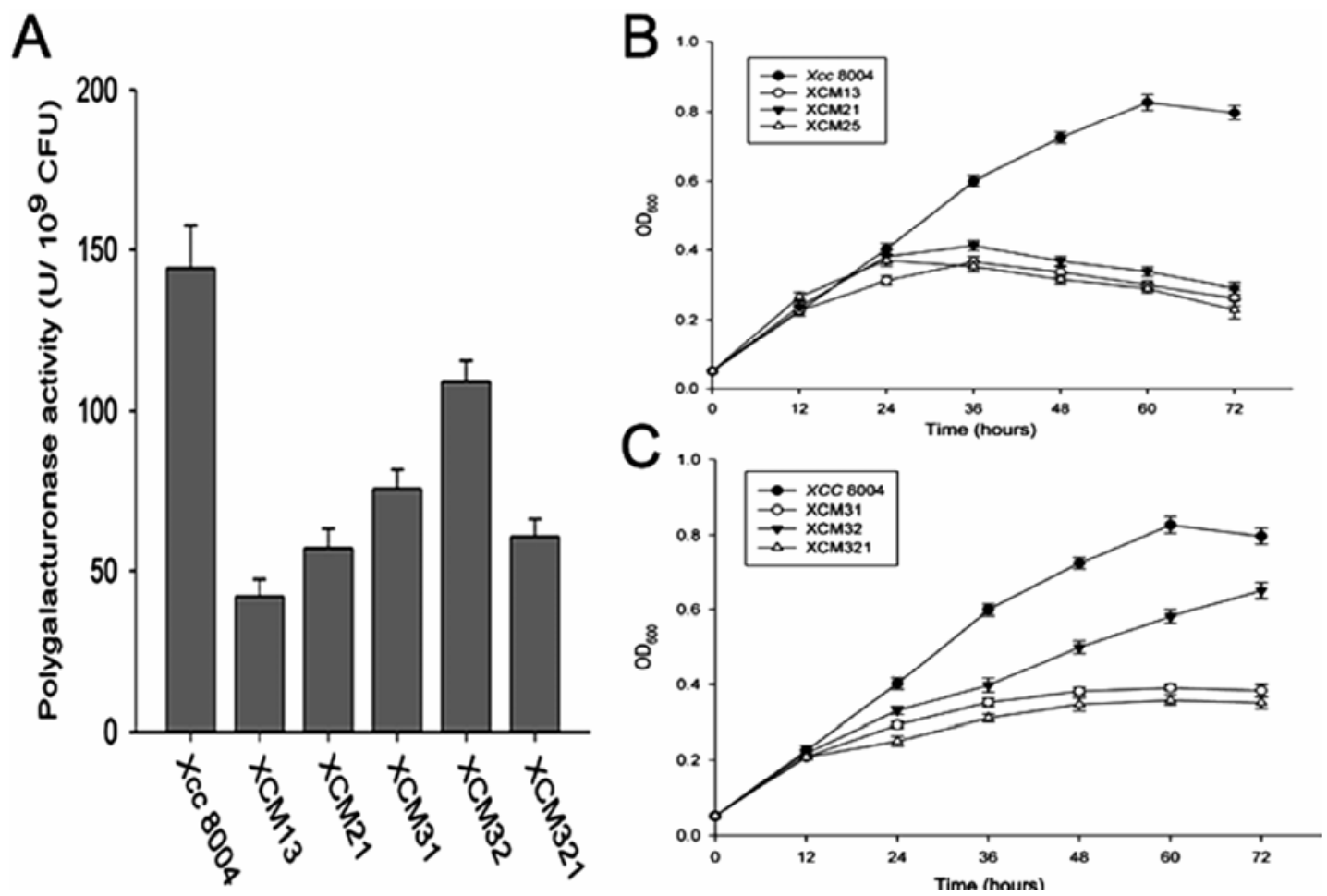

Fig. 5. A, Activity assays of the secreted polygalacturonases (PG) in the culture fluids of Xanthomonas campestris pv. campestris 8004, XCM13 (the hrpX mutant), XCM21 (the $c l p$ mutant), XCM31 (the $p g h A x c$ mutant), XCM32 (the pghBxc mutant), and XCM321 (the $p g h A x c$ and $p g h B x c$ double mutant). Error bars represent standard deviations. A unit liberates $1 \mu \mathrm{mol}$ galacturonic acid from polygalacturonic acid per minute. $\mathbf{B}$ and $\mathbf{C}$, Bacterial growth curves of strains used in PG activity assays. Strains were cultured in minimal medium using polygalacturonic acid as the sole carbon source, and samples were taken every $12 \mathrm{~h}$. This experiment was repeated five times, and error bars represent standard deviations. 
campestris 8004, which further confirms the secretion dependency of PghAxc and PghBxc on the Xps proteins of the T2SS (Fig. 4B).

\section{The hydrolytic activities of PghAxc and PghBxc.}

To test the activities and virulence of these two PG (PghAxc and PghBxc), we generated the mutants $p g h A x c$ and $p g h B x c$ as well as the double mutant. Activity assays were performed in $X$. campestris pv. campestris 8004, XCM31 (the pghAxc mutant), XCM32 (the pghBxc mutant), and XCM321 (the double mutant). All the mutants showed lower hydrolytic activities compared to the wild type, especially the pghAxc mutant and the double mutant (Fig. 5A). The results of these activity assays suggested that PghAxc contributed more to the full $X$. campestris pv. campestris PG activities than did PghBxc. Furthermore, we also recorded the dynamic population growth of these strains in minimal medium using the polygalacturonic acids as the sole carbon source. The results showed that the wild type always had a growth advantage compared with the mutants, which is consistent with the activity assays. In addition, dynamic growth of XCM13 (the hrpX mutant), XCM21 (the clp mutant), and XCM25 (the xpsE mutant) showed that, as opposed to the increased growth of the wild-type $X$. campestris pv. campestris 8004 , the growth of the three mutants trended downwards after being cultured for $36 \mathrm{~h}$ in minimal medium (Fig. 5B). This result suggested that mutation of these genes would disadvantage the growth of bacteria in the minimal medium using polygalacturonic acids as the sole carbon source.

\section{pghAxc and pghBxc are required for full virulence} of $X$. campestris pv. campestris in Arabidopsis.

Dip-, spray-, and infiltration-inoculation methods were used in pathogenicity tests. We have tested several ecotypes of Arabidopsis and have found that the ecotype Kendle is most suitable for the assay. The inoculants for the pathogenicity
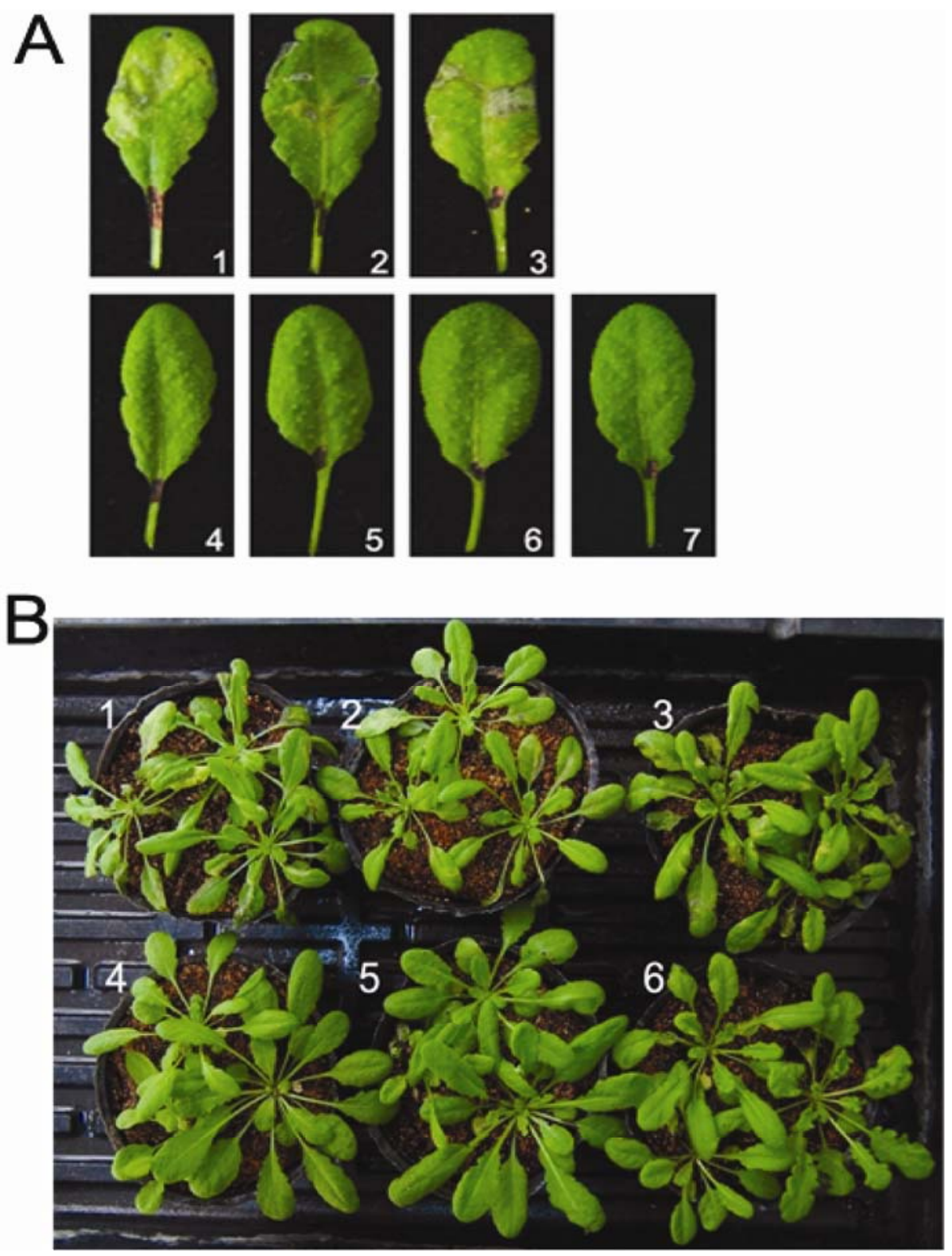

Fig. 6. A, Typical symptoms of disease elicited by Xanthomonas campestris pv. campestris strains using dip- and $\mathbf{B}$, spray-inoculation methods in Arabidopsis. The inoculants were X. campestris pv. campestris 8004 (1), the pghAxc mutant (5), and complemented strain (2), the pghBxc mutant (6) and complemented strain (3), the $p g h A x c$ and $p g h B x c$ double mutant (4), and mock-inoculated $(10 \mathrm{mM} \mathrm{MgCl} 2)$ (7). Bacterial density was $3 \times 10^{8} \mathrm{CFU} / \mathrm{ml}$ for dip and spray inoculation. 
tests were $X$. campestris pv. campestris 8004, XCM31 (the pghAxc mutant), XCM32 (the pghBxc mutant), and XCM321 (the $p g h A x c$ and $p g h B x c$ double mutant). The results showed that the wild type caused distinctive necrosis symptoms compared with the mutants and the double mutant, all of which elicited weak symptoms with a minor wilt in both dip- (Fig. 6A) and spray-inoculation assays (Fig. 6B). The mutant-complemented strains of both pghAxc and pghBxc were able to elicit the same distinctive necrosis symptoms as the wild type (Fig. 6). However, no differences could be found between the wild type and the mutants using the infiltration method (data not shown). These results suggest that $p g h A x c$ and pghBxc are required for full virulence of the bacteria in Arabidopsis. Moreover, we also assayed the bacterial growth in Arabidopsis by

Table 2. Bacterial strains and plasmids used in this study

\begin{tabular}{|c|c|c|}
\hline $\begin{array}{l}\text { Strains or } \\
\text { plasmids }\end{array}$ & Relevant characteristics $^{\mathbf{a}}$ & $\begin{array}{l}\text { Reference } \\
\text { or source }\end{array}$ \\
\hline \multicolumn{3}{|c|}{ Xanthomonas campestris pv. campestris strains } \\
\hline 8004 & Wild-type; Rif $^{\mathrm{r}}$ & Turner et al. 1984 \\
\hline XCM13 & $\begin{array}{l}\text { hrpX } \mathrm{pK} 18 \text { knockout mutant; } \\
\text { Rif }^{\mathrm{r}}, \mathrm{Km}^{\mathrm{r}}\end{array}$ & Wang et al. 2007 \\
\hline XCM21 & $\begin{array}{l}c l p \text { pK18 knockout mutant; } \\
\text { Rif }^{\mathrm{r}}, \mathrm{Km}^{\mathrm{r}}\end{array}$ & This study \\
\hline XCM31 & $\begin{array}{l}\text { phgAxc pK18 knockout } \\
\text { mutant; } \text { Rif }^{\mathrm{r}}, \mathrm{Km}^{\mathrm{r}}\end{array}$ & This study \\
\hline XCM31C & $\begin{array}{l}\text { phgAxc mutant containing } \\
\text { pHMpghAxc }\end{array}$ & This study \\
\hline XCM32 & $\begin{array}{l}\text { phgBxc pK18 knockout } \\
\text { mutant; } \text { Rif }^{\mathrm{r}}, \mathrm{Km}^{\mathrm{r}}\end{array}$ & This study \\
\hline $\mathrm{XCM} 32 \mathrm{C}$ & $\begin{array}{l}\text { phgBxc mutant containing } \\
\text { pHMpghBxc }\end{array}$ & This study \\
\hline XCM321 & $\begin{array}{l}\text { phgAxc and phgBxc double } \\
\text { mutant; } \mathrm{Km}^{\mathrm{r}} \text { and } \mathrm{Sp}^{\mathrm{r}}\end{array}$ & This study \\
\hline $\mathrm{XCM} 25$ & $\begin{array}{l}\text { xpsE Tn5-insertion mutant; } \\
\operatorname{Rif}^{\mathrm{r}}, \mathrm{Km}^{\mathrm{r}}\end{array}$ & Sun et al 2003 \\
\hline XCM26 & $\begin{array}{l}\text { xpsD Tn5-insertion mutant; } \\
\text { Rif }^{\mathrm{r}}, \mathrm{Km}^{\mathrm{r}}\end{array}$ & Sun et al 2003 \\
\hline \multicolumn{3}{|l|}{ Plasmids } \\
\hline $\begin{array}{l}\text { pGEM-T easy } \\
\text { pHM1 }\end{array}$ & $\begin{array}{l}\text { PCR cloning vector, Amp }{ }^{\mathrm{r}} \\
\text { Broad-host range } \cos \text { parA }\end{array}$ & Promega \\
\hline & $\begin{array}{l}\text { IncW derivative of pRI40 } \\
\text { Spr, Strr }\end{array}$ & Innes et al. 1988 \\
\hline pHMpghAxc & $\begin{array}{l}\text { pHM } 1 \text { containing full length of } \\
\text { pghAxc gene }\end{array}$ & This study \\
\hline pHMpghBxc & $\begin{array}{l}\text { pHM1 containing full length of } \\
\text { pghBxc gene }\end{array}$ & This study \\
\hline pHMpghAxcMyc & $\begin{array}{l}\text { pHM1 containing Myc-tagged } \\
\text { pghAxc }\end{array}$ & This study \\
\hline pHMpghBxcMyc & $\begin{array}{l}\text { pHM1 containing Myc-tagged } \\
\text { pghBxc }\end{array}$ & This study \\
\hline pK18mob & $\begin{array}{l}\text { Suicide plasmid in } X . \text { cam- } \\
\text { pestris pv. campestri; } \mathrm{Km}^{\mathrm{r}}\end{array}$ & Schafer et al. 1994 \\
\hline pKpA & pghAxc knockout construct & This study \\
\hline $\mathrm{pKpB}$ & pghBxc knockout construct & This study \\
\hline pK18hrpX & hrpX knockout construct & This study \\
\hline pKnockout $-\Omega$ & $\begin{array}{l}\text { Suicide plasmid in } X . \\
\text { campestris pv. campestri; } \mathrm{Sp}^{\mathrm{r}}\end{array}$ & Lab collection \\
\hline pKopB & $\begin{array}{l}p g h B x c \text { knockout construct de- } \\
\text { rived from pKnockout- } \Omega ; \mathrm{Sp}^{\mathrm{r}}\end{array}$ & This study \\
\hline pL6GUS & $\begin{array}{l}\text { pLAFR6 contains } \\
\text { promotorless uidA gene in } \\
\text { multiple cloning sites, } \\
\text { promoter-probe vector }\end{array}$ & Lab collection \\
\hline pPEGGUS & $\begin{array}{l}\text { pLAFR6 carrying } p g h A x c \\
\text { promoter fused with uidA }\end{array}$ & This study \\
\hline pPPGGUS & $\begin{array}{l}\text { pLAFR6 carrying } p g h B x c \\
\text { promoter fused with uidA }\end{array}$ & This study \\
\hline pRK2013 & $\begin{array}{l}\text { ColE1 replicon } \mathrm{TraRK}^{+} \mathrm{Mob}^{+} \\
\mathrm{Km}^{\mathrm{r}}\end{array}$ & Lab collection \\
\hline
\end{tabular}

${ }^{\mathrm{a}}$ Rif $=$ rifampicin, $\mathrm{Km}=$ kanamycin, $\mathrm{Amp}=$ ampicillin, $\mathrm{Sp}=$ spectinomycin, $\mathrm{Str}=$ streptomycin, $\mathrm{Gm}=$ gentamycin, $\mathrm{Tc}=$ tetracycline; ${ }^{\mathrm{r}}=$ resistant. infiltration inoculation, and the results showed only minor differences between the wild type and the mutants (data not shown).

\section{DISCUSSION}

Earlier studies of PG in Erwinia spp. and $R$. solanacearum mainly focused on the aspects of the enzyme activity and virulence (Gonzalez and Allen 2003; Huang and Allen 1997; Lei et al. 1985; Liu et al. 2005). In this study, two novel PG genes from $X$. campestris pv. campestris have been characterized. Their hydrolytic enzyme activity and virulence functions have been more comprehensively assayed and the regulation of their expression has been defined, which provides evidence of some linkages between the T2SS and the T3SS. Furthermore, we showed that the expressions of these two PG in planta are strongly inducible.

Alignments of the amino-acid sequences of all the PG from the three phytopathogens showed a low identification of PghAxc (about 30\%) and PghBxc (about 17\%) to the homologs from Erwinia spp. and $R$. solanacearum, suggesting that these proteins have a degree of novelty. However, within the Xanthomonas species, those two PG are relatively conserved (over $70 \%$ sequence identity). These facts suggested that PG in different pathogenic species were divergent and may evolve differently according to host preference and environmental surroundings. In addition, the computational comparison among all the published sequences of PG also revealed numbers of conserved regions, suggesting they may be required for the common functions of substrate binding and hydrolysis of PG.

Although some genes not belonging to the T3SS are thought to belong to the HrpX regulon (da Silva et al. 2002), only one gene encoding the extracellular (CysP2) T2SS enzyme has so far been demonstrated to be regulated by HrpX (Furutani et al. 2004). CysP2 is an extracellular protease that contains an imperfect PIP box in its promoter region. Using GUS assays, RTPCR, and silver-stain approaches, the authors demonstrated the HrpX-dependency of cysP2's expression (Furutani et al. 2004). In our study, we found two novel PG from $X$. campestris pv. campestris with HrpX-dependent expression. HrpX is the key regulator in the T3SS that controls the expression of

Table 3. Primers used in this study ${ }^{\mathrm{a}}$

\begin{tabular}{|c|c|c|}
\hline $\begin{array}{l}\text { Gene } \\
\text { target }\end{array}$ & Primer sequence $\left(5^{\prime} \rightarrow 3^{\prime}\right)$ & $\begin{array}{l}\text { Restriction } \\
\text { site added }\end{array}$ \\
\hline $\operatorname{pgh} A x c$ & & $\ldots$ \\
\hline Axck-F & CAGCGCATTTACGCTCTAC & $\ldots$ \\
\hline Axck-R & CAACATTGGCAAGCACCAGG & \\
\hline Axcp-F & CCCAAGCTTGGAGATGGTGCAGTTCCAG & HindIII \\
\hline Axcp-R & CGGGATCCACGTAGTCACCCGAAGAAG & BamHI \\
\hline Axcm-F & CAAGCTTCTTCGGGTGACTACGTCATG & HindIII \\
\hline Axcm-R & $\begin{array}{l}\text { GGTACCTTACAGATCTTCTTCAGAAATA } \\
\text { AGTTTTTGTTcCAACGCAGGAAAGTGC } \\
\text { GGTG }\end{array}$ & $K p n \mathrm{I}$ \\
\hline \multicolumn{3}{|c|}{$e_{0}$} \\
\hline Bxck-F & ATCCCАCCCAАTCCAAACGC & $\ldots$ \\
\hline Bxck-R & GAAGCATCGGACTTGATACGC & \\
\hline Bxcp-F & $\begin{array}{l}\text { CCCCAAGCTTGTACGGCTTGTTGCCTTA } \\
\text { G }\end{array}$ & HindIII \\
\hline Bxcp-R & CGGGATCCAGTGGGAGAGAGGTGAC & BamHI \\
\hline Bxcm-F & CAAGCTTCACTGGAGTCAAACGGAATG & HindIII \\
\hline $\mathrm{Bxcm}-\mathrm{R}$ & $\begin{array}{l}\text { GAATTCTTACAGATCTTCTTCAGAAATA } \\
\text { AGTTTTTGTTCGACGGCTGCGGCGCCG } \\
\text { TCGG }\end{array}$ & EcoRI \\
\hline
\end{tabular}


hrp and some effector genes. The fact that HrpX is also involved in the regulation of some extracellular enzymes of the T2SS suggests that HrpX controls the expression of the majority of genes containing a PIP box in Xanthomonas spp. and, therefore, may be involved in regulation of many Xanthomonas genes. This regulation of HrpX suggested that the signal transduction networks of pathogens are cross-linked and that the T3SS and T2SS may cooperate via various regulators to promote the virulence of the pathogen in the host. However, the PG activity assay showed that, in XCM13 (the hrpX mutant) and XCM321 (the pghAxc and pghBxc double mutant), PG activity (up to approximately $30 \%$ of the wild-type strain) could be detected, suggesting that additional functional PG exists in Xanthomonas spp. HrpG, a two-component response regulator, is the upstream regulatory factor of $\mathrm{HrpX}$ and controls the regulatory cascade of the T3SS in Xanthomonas spp. The results showed that the regulatory activity of HrpG is weaker than that of HrpX. Moreover, with the hrpX gene mutated, HrpG would lose most of its regulatory controls on the PG even if $h r p G$ is overexpressed. These results suggested that HrpG was indirectly involved in PG regulation but the regulation was HrpX-dependent. Therefore, we speculated that the regulation HrpG on the pghAxc may be achieved via HrpX and that the PG belonged to the HrpG/HrpX regulon.

Clp of $X$. campestris pv. campestris is a member of the conserved global-regulator family. The most representative protein of this family is Crp of E. coli. This regulator has been extensively studied and has been shown to directly regulate about 192 genes (He et al. 2007; Martinez-Antonio and ColladoVides 2003; Zheng et al. 2004). Similar to Crp, Clp in $X$. campestris pv. campestris also influences the expression of a number of genes, especially the genes in the T2SS (He et al. 2007). A recent study showed direct binding of Clp to the promoter region of engXCA, which is a cellulase secreted via the T2SS (Hsiao et al. 2005). Another example of a Clp-regulated extracellular enzyme is PRT1, which is a protease secreted via the T2SS that is responsible for $X$. campestris pv. campestris virulence (Dow et al. 1990; Hsiao and Tseng 2002). Our data showed that pghAxc and pghBxc are regulated by Clp, which agreed with previous studies showing that Clp is involved in the expression of extracellular enzymes of T2SS (He et al. 2007; Hsiao et al. 2005; Martinez-Antonio and Collado-Vides 2003; Zheng et al. 2004). However, analysis of the promoter regions of PG genes only identified the conserved sequences of Clp binding sites 'TGTGA-N6-TCACA' (Dong and Ebright $1992)$ in the promoter of $p g h B x c$. Therefore, it is reasonable to predict that $p g h B x c$ may be regulated by Clp directly by binding to the box and that $p g h A x c$ may affect regulation in another indirect way. A similar situation has also been found in Clpregulated PRT1 (Dow et al. 1990; Hsiao and Tseng 2002). Some regulatory proteins may directly regulate the expression of pghAxc and, in turn, those regulators may require the function of Clp. That is to say, Clp regulation of PG genes may be achieved in a cascade manner. From the reports of He and associates (2007), some genes belonging to the T3SS are regulated by Clp, which is also evidence that the T2SS and T3SS are cross-linked.

The PG of phytopathogens have been classified to the CWDE secreted via the T2SS. This is mainly based on the Nterminal signal peptide of PG and the severe effects on extracellular enzyme activity by deficiencies of the T2SS. Xanthomonas protein secretion (xps) genes encode structural proteins to form the secretion channel of the T2SS, which is essential for the secretion of the T2SS extracellular enzymes (Hu et al. 1998; Ray et al. 2000). We provided direct evidence of T2SS-dependent secretion of PG using immunoblot detection in the culture fluids of wild-type and xps mutants.
The ability to degrade pectin is useful for pathogens in virulence. During pathogenesis, plant cell walls act as the first barrier of defense against bacterial invasion and multiplication. The enzymatic activities of pectin degradation may facilitate pathogen invasion into the cells of its host plants by digesting the pectin layers of plant cells. Our data showed that the virulence of $p g h A x c$ and $p g h B x c$ mutants was attenuated in Arabidopsis using dip- and spray-inoculation methods. Dip and spray inoculation showed the distinctive differences in virulence between the wild type and mutants, while the infiltration method did not. This fact suggested that the virulence function of PghAxc and PghBxc may mainly execute in the early stage of bacterial pathogenesis, which is the process for pathogens to overcome the pectin barriers of plant cells. Furthermore, the expression of those two PG could be more efficiently induced in planta $36 \mathrm{~h}$ postinoculation, which also suggested that the PG were required for the bacterial virulence in the early stage of pathogenesis in planta. Additionally, in the infiltration-inoculation method, the bacteria are syringed directly into the intercellular spaces of plant cells, which artificially overcomes the epidermis of the leaves. Alternatively, the barely detectable differences in disease symptoms using infiltration inoculation may be explained by functional redundancy. The $X$. campestris $\mathrm{pv}$. campestris genome annotation has revealed different isoforms of CWDE as well as numerous virulence factors that are associated with bacterial pathogenesis. Therefore, the result that losing one or two CWDE did not cause a distinctive difference on the $X$. campestris pv. campestris virulence could be expected.

\section{MATERIALS AND METHODS}

\section{Bacterial strains and growth conditions.}

The bacterial strains and plasmids used in this study are listed in Table 2. X. campestris pv. campestris 8004 was grown in NYGB medium (Tsuchiya et al. 1982) or in a plant-mimicking minimal medium, MMXC (MMX [Daniels et al. 1984], plus $10 \mathrm{mM}$ sucrose, $10 \mathrm{mM}$ fructose, $4 \mathrm{mM}$ sodium glutamate, and $0.03 \%$ casamino acids) at $28^{\circ} \mathrm{C}$. E. coli strains were grown in Luria-Bertani medium at $37^{\circ} \mathrm{C}$. Antibiotics were used at the following concentrations: ampicillin at $100 \mu \mathrm{g} / \mathrm{ml}$, kanamycin at $50 \mu \mathrm{g} / \mathrm{ml}$, rifampicin at $50 \mu \mathrm{g} / \mathrm{ml}$, tetracycline at 15 $\mu \mathrm{g} / \mathrm{ml}$ for $X$. campestris pv. campestris 8004 and $50 \mu \mathrm{g} / \mathrm{ml}$ for $E$. coli, and spectinomycin at $100 \mu \mathrm{g} / \mathrm{ml}$ for $X$. campestris $\mathrm{pv}$. campestris 8004 and $50 \mu \mathrm{g} / \mathrm{ml}$ for E. coli.

\section{Mutant generation.}

To obtain knock-out mutants, the truncated fragments of pghAxc and pghBxc were amplified with primers Axck and Bxck and were cloned into pGEM-T Easy vectors (Promega, Madison, WI, U.S.A.). After digestion by EcoRI, the fragment was cloned into the knock-out vector pK18mob (Schafer et al. 1994), giving $\mathrm{pKpA}$ and $\mathrm{pKpB}$. These two knock-out constructs were introduced into X. campestris pv. campestris 8004. By homologous recombination, the corresponding genes in the $X$. campestris pv. campestris 8004 genome were inserted using the pk18mob vector and separated into two functionless truncated fragments. For the double mutant, the truncated fragment of pghBxc was cloned into another knock-out vector pKnockout- $\Omega$ with spectinomycin resistance (Windgassen et al. 2000), giving $\mathrm{pKopB}$. Then the $\mathrm{pKopB}$ construct was introduced to the pghAxc knock-out mutant and was selected by adding both kanamycin and spectinomycin into the agar medium. Southern blot and PCR were used to confirm all the mutant candidates. The knock-out mutant of $h r p X$ (XCM13) was obtained similarly (Wang et al. 2007). 
DNA manipulation and plasmid construction.

DNA isolation, restriction enzyme digestion, agarose gel electrophoresis, subcloning, electroporation, PCR, Southern, and Western blot analyses were performed according to standard procedures (Sambrook et al. 1989). The PCR primers were listed in Table 3. All the PCR products used in cloning were first cloned into the pGEM-T Easy vector (Promega) and were verified by sequencing.

To construct pgh promoter-GUS fusion constructs, the whole promoter region of $p g h$ was amplified with primers Axcp and Bxcp. The fragments were cloned into the promoter probe plasmid pL6GUS with HindIII and BamHI, giving pPEGGUS and pPPGGUS. To express the Myc-tagged PG protein, the whole $p g h$ gene was Myc-tagged at the $3^{\prime}$-terminus by PCR, using primers $\mathrm{Axcm}$ and $\mathrm{Bxcm}$, and then, was cloned into the vector pHM1, giving pPghAMyc and pPghBMyc. The two constructs were introduced into wild type, giving the $x p s E$ (XCM25) and $x p s D$ (XCM26) mutants for secretion detection.

\section{Protein preparations and enzyme activity assays.}

Extracellular proteins were prepared collecting the supernatants of $X$. campestris pv. campestris cultures grown in MMXC medium for 72 to $96 \mathrm{~h}$. For viscosity assays, the supernatants were concentrated approximately 30 -fold by freeze drying and were dialyzed at $4{ }^{\circ} \mathrm{C}$ overnight against $0.5 \mathrm{mM}$ acetate buffer, $\mathrm{pH}$ 5.0. Endo-PG activity was measured as rate of viscosity change in a substrate solution containing $1 \%$ polygalacturonic acid in $50 \mathrm{mM}$ sodium acetate, $\mathrm{pH} 5.0$. Concentrated culture supernatant $(1 \mathrm{ml})$ was added to $14 \mathrm{ml}$ of substrate solution in an Ubbelohde Viscometer Capillary at $28^{\circ} \mathrm{C}$.

\section{Detection of secretory PG proteins}

\section{of $X$. campestris pv. campestris in MMXC.}

For the secretion assay, strains of $X$. campestris pv. campestris 8004 and $x p s E$ (XCM25), and xpsD (XCM26) mutants carrying pPghAMyc or pPghBMyc, respectively, were cultured in NYGB medium for $30 \mathrm{~h}$ at $28^{\circ} \mathrm{C}$. The procedures for protein preparation and immunoblot were performed as before (Wang et al. 2007).

\section{Promoter activity assay and RT-PCR analysis.}

For GUS activity assays, X. campestris pv. campestris 8004 and mutant strains were cultured in MMXC to an optical density at $600 \mathrm{~nm}\left(\mathrm{OD}_{600}\right)=0.5$. Bacteria cells were diluted and disrupted in sonic buffer (20 mM Tris $\mathrm{HCl}, \mathrm{pH} 7.0,10 \mathrm{mM} 2-$ mercaptoethanol, $5 \mathrm{mM}$ EDTA, and 1\% Triton X-100). GUS activity was assayed as described previously (Jefferson et al. 1987). One unit was defined as 1 nmol of 4-methyl-umbelliferone produced per minute per bacterium. For RT-PCR analysis in vivo, the bacteria were cultured exactly as for the GUS activity assay $\left(\mathrm{OD}_{600}=0.5\right)$ and were infiltrated into leaves of Arabidopsis. Total RNA was extracted using Trizol reagent according to the manufacturer's instructions (Invitrogen, Carlsbad, CA, U.S.A.). Total RNA were quantified by measuring the $\mathrm{OD}_{260}$ and were qualified by gel electrophoresis. Before synthesis of the first strands, total RNA was digested with RNase-free DNAse I (TaKaRa, Dalian, China) to remove potential traces of genomic DNA. cDNA synthesis and PCR were conducted with a Superscript one-step RT-PCR kit (Invitrogen) and ex-Taq DNA polymerases (TaKaRa) with the primers Axck and Bxck.

\section{RT-PCR assay.}

Arabidopsis leaf samples were harvested from uninoculated plants and inoculated plants at $0,12,24,36,48$, and $60 \mathrm{~h}$ after inoculation. Total RNA from inoculated Arabidopsis leaf tissues was extracted using Trizol reagent (Invitrogen) according to the manufacturer's instructions. First-strand cDNA was synthesized using the SuperScript first-strand synthesis system (Invitrogen) after digestion with RNase-free DNase I (TaKaRa). PCR reactions were carried out using the synthesized cDNA products as templates with primers Axck and Bxck specific for pghAxc and $p g h B x c$, respectively. The products of RT-PCR were detected by electrophoresis on a $1.0 \%$ agarose gel and were stained with ethidium bromide.

\section{Pathogenicity assay.}

Arabidopsis grown in a greenhouse for over 1 month were used for pathogenicity tests. After washing twice with $10 \mathrm{mM}$ $\mathrm{MgC}_{12}$, bacteria at the correct optical densities were inoculated into the leaves by dip and spray inoculation at $3 \times 10^{8} \mathrm{CFU}$ per milliliter and infiltration at $1 \times 10^{6} \mathrm{CFU}$ per milliliter.

\section{PG activity (reducing sugar ends assays) and dynamic population-growth assays.}

To test the PG activity and dynamic population growth, we used MMXG medium $\left(\mathrm{K}_{2} \mathrm{HPO}_{4}, 10.5 \mathrm{~g} / \mathrm{liter} ; \mathrm{KH}_{2} \mathrm{PO}_{4}, 4.5\right.$ g/liter; $\left(\mathrm{NH}_{4}\right)_{2} \mathrm{SO}_{4}, 1.0$ g/liter; $\mathrm{MgSO}_{4}, 1 \mathrm{mM}$; polygalacturonic acid, $0.5 \%$ (wt/vol), $\mathrm{pH}$ 6.0) modified from MMX with polygalacturonic acid as the sole carbon source. Extracellular protein preparations were made by collecting the supernatants from 72- to $96-\mathrm{h} X$. campestris pv. campestris cultures grown in MMXG minimal medium. For PG assays, these supernatants were concentrated and measured quantitatively as reducing sugar ends released, using the method of Huang and Allen (1997). One unit of PG activity was defined as the amount of enzyme that releases $1 \mathrm{mmol}$ of oligogalacturonate from PGA per minute. For dynamic population-growth assays, the $X$. campestris pv. campestris strains were cultured first in NYG for $30 \mathrm{~h}$, and then, were washed with $10 \mathrm{mM} \mathrm{MgC}$. Strains were diluted to $\mathrm{OD}_{600}=0.1$ and were cultured in $\mathrm{MMXG}$ minimal medium. Every $12 \mathrm{~h}, 500-\mu \mathrm{l}$ samples of each strain were taken for $\mathrm{OD}_{600}$ measurements.

\section{ACKNOWLEDGMENTS}

This work was funded by the Knowledge Innovation Program of the Chinese Academy of Sciences (grant KSCX2-YW-N-005) and the National Natural Science Foundation of China (grant 30228002).

\section{LITERATURE CITED}

Allen, C., Gay, J., and Simon-Buela, L. 1997. A regulatory locus, pehSR, controls polygalacturonase production and other virulence functions in Ralstonia solanacearum. Mol. Plant-Microbe Interact. 10:1054-1064.

Buttner, D., and Bonas, U. 2002. Getting across-Bacterial type III effector proteins on their way to the plant cell. EMBO (Eur. Mol. Biol Organ.) J 21:5313-5322.

Chen, L. Y., Chen, D. Y., Miaw, J., and Hu, N. T. 1996. XpsD, an outer membrane protein required for protein secretion by Xanthomonas campestris pv. campestris, forms a multimer. J. Biol. Chem. 271:27032708.

Collmer, A., and N. T. Keen. 1986. The role of pectic enzymes in plant pathogenesis. Annu. Rev. Phytopathol. 24:383-409.

da Silva, A. C., Ferro, J. A., Reinach, F. C., Farah, C. S., Furlan, L. R., Quaggio, R. B., Monteiro-Vitorello, C. B., Van Sluys, M. A., Almeida, N. F., Alves, L. M., do Amaral, A. M., Bertolini, M. C., Camargo, L. E., Camarotte, G., Cannavan, F., Cardozo, J., Chambergo, F., Ciapina, L. P., Cicarelli, R. M., Coutinho, L. L., Cursino-Santos, J. R., El-Dorry, H., Faria, J. B., Ferreira, A. J., Ferreira, R. C., Ferro, M. I., Formighieri, E. F., Franco, M. C., Greggio, C. C., Gruber, A., Katsuyama, A. M., Kishi, L. T., Leite, R. P., Lemos, E. G., Lemos, M. V., Locali, E. C., Machado, M. A., Madeira, A. M., Martinez-Rossi, N. M., Martins, E. C., Meidanis, J., Menck, C. F., Miyaki, C. Y., Moon, D. H., Moreira, L. M., Novo, M. T., Okura, V. K., Oliveira, M. C., Oliveira, V. R., Pereira, H. A., Rossi, A., Sena, J. A., Silva, C., de Souza, R. F., Spinola, L. A., Takita, M. A., Tamura, R. E., Teixeira, E. C., Tezza, R. 
I., Trindade dos Santos, M., Truffi, D., Tsai, S. M., White, F. F., Setubal, J. C., and Kitajima, J. P. 2002. Comparison of the genomes of two Xanthomonas pathogens with differing host specificities. Nature 417:459-463

Daniels, M. J., Barber, C. E., Turner, P. C., Sawczyc, M. K., Byrde, R. J., and Fielding, A. H. 1984. Cloning of genes involved in pathogenicity of Xanthomonas campestris pv. campestris using the broad host range cosmid pLAFR1. EMBO (Eur. Mol. Biol. Organ.) J 3:3323-3328.

de Crecy-Lagard, V., Glaser, P., Lejeune, P., Sismeiro, O., Barber, C. E., Daniels, M. J., and Danchin, A. 1990. A Xanthomonas campestris pv. campestris protein similar to catabolite activation factor is involved in regulation of phytopathogenicity. J. Bacteriol. 172:5877-5883.

Dong, Q., and Ebright, R. H. 1992. DNA binding specificity and sequence of Xanthomonas campestris catabolite gene activator protein-like protein. J. Bacteriol. 174:5457-5461.

Dow, J. M., and Daniels, M. J. 1994. Pathogenicity determinants and global regulation of pathogenicity of Xanthomonas campestris pv. campestris. Curr. Top. Microbiol. Immunol. 192:29-41.

Dow, J. M., Clarke, B. R., Milligan, D. E., Tang, J. L., and Daniels, M. J. 1990. Extracellular proteases from Xanthomonas campestris pv. campestris, the black rot pathogen. Appl. Environ. Microbiol. 56:2994-2998.

Dow, J. M., Davies, H. A., and Daniels, M. J. 1998. A metalloprotease from Xanthomonas campestris that specifically degrades proline/hydroxyproline-rich glycoproteins of the plant extracellular matrix. Mol. PlantMicrobe Interact. 11:1085-1093.

Furutani, A., Tsuge, S., Ohnishi, K., Hikichi, Y., Oku, T., Tsuno, K., Inoue, Y., Ochiai, H., Kaku, H., and Kubo, Y. 2004. Evidence for HrpXo-dependent expression of type II secretory proteins in Xanthomonas oryzae pv. oryzae. J. Bacteriol. 186:1374-1380.

Furutani, A., Nakayama, T., Ochiai, H., Kaku, H., Kubo, Y., and Tsuge, S 2006. Identification of novel HrpXo regulons preceded by two cis-acting elements, a plant-inducible promoter box and a -10 box-like sequence, from the genome database of Xanthomonas oryzae pv. oryzae. FEMS (Fed. Eur. Microbiol. Soc.) Microbiol. Lett. 259:133-141.

Gonzalez, E. T., and Allen, C. 2003. Characterization of a Ralstonia solanacearum operon required for polygalacturonate degradation and uptake of galacturonic acid. Mol. Plant-Microbe Interact. 16:536-544.

He, Y. W., Ng, A. Y., Xu, M., Lin, K., Wang, L. H., Dong, Y. H., and Zhang, L. H. 2007b. Xanthomonas campestris cell-cell communication involves a putative nucleotide receptor protein Clp and a hierarchical signalling network. Mol. Microbiol. 64:281-292.

Hsiao, Y. M., and Tseng, Y. H. 2002. Transcription of Xanthomonas campestris prt1 gene encoding protease 1 increases during stationary phase and requires global transcription factor Clp. Biochem. Biophys. Res. Commun. 295:43-49.

Hsiao, Y. M., Liao, H. Y., Lee, M. C., Yang, T. C., and Tseng, Y. H. 2005. Clp upregulates transcription of engA gene encoding a virulence factor in Xanthomonas campestris by direct binding to the upstream tandem Clp sites. FEBS (Fed. Eur. Biochem. Soc.) Lett. 579:3525-3533

Hu, N. T., Hung, M. N., Chen, D. C., and Tsai, R. T. 1998. Insertion mutagenesis of XpsD, an outer-membrane protein involved in extracellular protein secretion in Xanthomonas campestris pv. campestris. Microbiology 144 (Pt 6):1479-1486.

Huang, Q., and Allen, C. 1997. An exo-poly-alpha-D-galacturonosidase, $\mathrm{PehB}$, is required for wild-type virulence of Ralstonia solanacearum. J. Bacteriol. 179:7369-7378.

Hugouvieux-Cotte-Pattat, N., Condemine, G., Nasser, W., and Reverchon, S. 1996. Regulation of pectinolysis in Erwinia chrysanthemi. Annu Rev Microbiol 50:213-257.

Hugouvieux-Cotte-Pattat, N., Shevchik, E. V., and Nasser, W. 2002. PehN, a polygalacturonase homologue with a low hydrolase activity, is coregulated with the other Erwinia chrysanthemi polygalacturonases. J. Bacteriol. 184:2664-2673.

Innes, R. W., Hirose, M. A., and Kuempel, P. L. 1988. Induction of nitrogenfixing nodules on clover requires only 32 kilobase pairs of DNA from the Rhizobium trifolii symbiosis plasmid. J. Bacteriol. 170:3793-3802.

Jefferson, R. A., Kavanagh, T. A., and Bevan, M. W. 1987. GUS fusions: Beta-glucuronidase as a sensitive and versatile gene fusion marker in higher plants. EMBO (Eur. Mol. Biol. Organ.) J. 6:3901-3907.

Kamoun, S., and Kado, C. I. 1990. A plant-inducible gene of Xanthomonas campestris pv. campestris encodes an exocellular component required for growth in the host and hypersensitivity on nonhosts. J. Bacteriol. 172:5165-5172.
Koebnik, R., Kruger, A., Thieme, F., Urban, A., and Bonas, U. 2006. Specific binding of the Xanthomonas campestris pv. vesicatoria AraC-type transcriptional activator HrpX to plant-inducible promoter boxes. J. Bacteriol. 188:7652-7660.

Lei, S. P., Lin, H. C., Heffernan, L., and Wilcox, G. 1985. Evidence that polygalacturonase is a virulence determinant in Erwinia carotovora. J. Bacteriol. 164:831-835.

Liu, H., Zhang, S., Schell, M. A., and Denny, T. P. 2005. Pyramiding unmarked deletions in Ralstonia solanacearum shows that secreted proteins in addition to plant cell-wall-degrading enzymes contribute to virulence. Mol. Plant-Microbe Interact. 18:1296-1305.

Martinez-Antonio, A., and Collado-Vides, J. 2003. Identifying global regulators in transcriptional regulatory networks in bacteria. Curr. Opin. Microbiol. 6:482-489.

Nasser, W., Shevchik, E. V., and Hugouvieux-Cotte-Pattat, N. 1999. Analysis of three clustered polygalacturonase genes in Erwinia chrysanthemi 3937 revealed an anti-repressor function for the PecS regulator. Mol. Microbiol. 34:641-650.

Noel, L., Thieme, F., Gabler, J., Buttner, D., and Bonas, U. 2003. XopC and XopJ, two novel type III effector proteins from Xanthomonas campestris pv. vesicatoria. J. Bacteriol. 185:7092-102.

Ray, S. K., Rajeshwari, R., and Sonti, R. V. 2000. Mutants of Xanthomonas oryzae pv. oryzae deficient in general secretory pathway are virulence deficient and unable to secrete xylanase. Mol. Plant-Microbe Interact. 13:394-401.

Sambrook, J., Fritsch, E. F., and Maniatis, T. 1989. Molecular Cloning: A Laboratory Manual. Cold Spring Harbor Laboratory Press, Cold Spring Harbor, NY, U.S.A

Sandkvist, M. 2001a. Biology of type II secretion. Mol Microbiol 40:271283.

Sandkvist, M. 2001b. Type II secretion and pathogenesis. Infect. Immun 69:3523-3535.

Schafer, A., Tauch, A., Jager, W., Kalinowski, J., Thierbach, G., and Puhler, A. 1994. Small mobilizable multi-purpose cloning vectors derived from the Escherichia coli plasmids pK18 and pK19: Selection of defined deletions in the chromosome of Corynebacterium glutamicum. Gene 145:69-73.

Sun, Q. H., Wu, W., Qian, W., Hu, J., Fang, R. X.and He, C. Z. 2003. High-quality mutant libraries of Xanthomonas oryzae pv. oryzae and $X$. campestris pv. campestris generated by an efficient transposon mutagenesis system. FEMS (Fed. Eur. Microbiol. Soc.) Microbiol. Lett. 226: $145-150$

Tsuchiya, K., Mew, T. W., and Wakimoto, S. 1982. Bacteriological and logical characteristics of wild types and induced mutants of Xanthomonas campestris pv. oryzae. Phytopathology 72:43-46.

Turner, P., Barber, C., and Daniels, M. 1984. Behavior of the transposons Tn 5 and Tn7 in Xanthomonas campestris pv. campestris. Mol. Gen. Genet. 195:101-107.

Valls, M., Genin, S., and Boucher, C. 2006. Integrated regulation of the type III secretion system and other virulence determinants in Ralstonia solanacearum. PloS Pathog. 2(8):e82.

Wang, L. F., Tang, X. Y., and He, C. Z. 2007. The bifunctinal effector AvrXccC of Xanthomonas campestris pv. campestris requires plasma membrane-anchoring for host recognition. Mol. Plant Pathol. 8:491501.

Wengelnik, K., Rossier, O., and Bonas, U. 1999. Mutations in the regulatory gene hrpG of Xanthomonas campestris pv. vesicatoria result in constitutive expression of all hrp genes. J. Bacteriol. 181:6828-6831.

Williams, P. H. 1980. Black rot: A continuing threat to world crucifers. Plant Dis. 64:736-745.

Windgassen, M., Urban, A., and Jaeger, K. E. 2000. Rapid gene inactivation in Pseudomonas aeruginosa. FEMS (Fed. Eur. Microbiol. Soc.) Microbiol. Lett. 193:201-5.

Zheng, D., Constantinidou, C., Hobman, J. L., and Minchin, S. D. 2004. Identification of the CRP regulon using in vitro and in vivo transcriptional profiling. Nucleic Acids Res. 32:5874-5893.

\section{AUTHOR-RECOMMENDED INTERNET RESOURCES}

Center for Biological Sequence Analysis SignalP server: www.cbs.dtu.dk/services/SignalP

Pfam website: www.sanger.ac.uk 